\title{
Exchange Rates, Exchange Risk, and Asian Export Revenue
}

\author{
WenShwo Fang \\ Feng Chia University, Overseas Chinese Institute of Technology \\ wsfang@fcu.edu.tw \\ YiHao Lai \\ Feng Chia University \\ yhlai@ocit.edu.tw \\ Henry Thompson \\ Auburn University \\ thomph1@auburn.edu
}

While depreciation may raise export revenue, associated exchange risk could offset any positive effect. The present paper investigates this net effect for eight Asian countries using a bivariate GARCH-M model that simultaneously estimates time varying risk. The fundamental result is that export markets react differently to exchange rates and associated risk. High degrees of risk apparently stimulate efforts to avoid its impact. Exchange risk has a dominating negative impact for the appreciating Japanese yen. Depreciation has no impact in Malaysia and Singapore, and exchange risk has a negative effect in Singapore. For the other five countries, depreciation stimulates export revenue but risk leads to a negative net effect in Taiwan.

Depreciation lowers the foreign currency price of exports and should increase export quantity.

Export revenue in domestic currency, however, may not rise and can fall. Perfectly inelastic foreign import demand would imply no increase in export revenue. If there is high import content in export production, depreciation could result in higher price of exports. With appreciation, exporters might price to market and lower their domestic currency price to maintain market share. Exporters may also actively hedge in option markets to avoid exchange rate effects. 
Theory is ambiguous and the empirical evidence on exchange rates and export revenue is mixed. Junz and Rhomberg (1973) and Wilson and Takacs (1979) find that devaluation increases export revenue for developed countries with fixed exchange rates, and Bahmani-Oskooee and Kara (2003) find similar results with flexible rates. In contrast, Athukorala (1991), Athukorala and Menon (1994), Abeysinghe and Yeok (1998), and Wilson and Tat (2001) find that appreciation does not lower export revenue in some Asian countries.

Even if there were a positive effect of depreciation on export revenue, associated exchange risk might discourage exporters and mitigate the positive effect. Exchange risk has become an issue since the collapse of fixed exchange rates in the early 1970s but there is no consensus regarding its impact on export revenue. Exchange risk could theoretically lower export revenue due to profit risk as developed by Ethier (1973). De Grauwe (1988) suggests, however, that exporters might increase volume to offset revenue loss. On the other side of the transactions, importers may seek other sources when facing exchange risk. Broll and Eckwert (1999) note the return on an option to export should increase along with risk. Exchange risk could also alter the currency inventory practices of exporters and importers. Reviewing the empirical literature, negative risk effects are found by Pozo (1992) for UK exports to the US; Chowdhury (1993) and Arize (1995, 1996, 1997) for US, European, and G7 exports; Weliwita, Ekanayake, and Tsujii (1999) for Sri Lanka's exports to six developed countries; and Arize, Osang, and Slottje (2000) and Arize, Malindretos, and Kasibhatla (2003) for LDC exports using a moving sample standard deviation model. In contrast, positive risk effects are found by Asseery and Peel (1991) for multilateral exports except for the UK; Kroner and Lastrapes (1993) for France, Germany, and Japan but 
negative effects for the UK and US; and McKenzie and Brooks (1997) for Germany and the US. Klaassen (2004) finds no risk effects for bilateral US exports to the other G7 countries.

Such contrary results motivate the present paper, the first to examine the net effect of depreciation and exchange risk simultaneously in a bivariate GARCH-M model. Monthly data covers the period 1979 to 2002 in Japan and seven developing Asian countries: Indonesia, Korea, Malaysia, Philippines, Singapore, Taiwan, and Thailand. Exports in these countries are found to respond differently to depreciation and risk.

\section{Time varying variances}

The present bivariate GARCH-M model differs from previous analysis in three ways. BahmaniOskooee and Kara (2003) and Wilson and Tat (2001) use cointegration techniques to examine the effect of depreciation on exports and the trade balance but Arize, Malindretos, and Kasibhatla (2003) show this technique overestimates the effect of depreciation when there is a negative risk effect. The present paper simultaneously estimates the effects of depreciation and risk.

Second, moving standard deviations of the exchange rate maintain the hypothesis of homoskedasticity while serving as a proxy for heteroskedastic risk in Chowdhury (1993), Arize, Osang, and Slottje (2000), and Arize, Malindretos, and Kasibhatla (2003). The present approach makes no such assumptions, improving upon models examining the relationship between means and variances as in Engle, Lilien, and Robins (1987) and Bollerslev, Chou, and Kroner (1992).

Third, exchange risk is conditional and time varying as shown by Hodrick and Srivastava (1984). GARCH methods allow time dependence as in Pozo (1992), McKenzie and Brooks (1997), and Weliwita, 
Ekanayake, and Tsujii (1999) but their two step procedure may result in inefficient estimation. The present method involves simultaneous bivariate estimation.

The nonstructural partial reduced form model utilized by Rose and Yellen (1989), Rose (1990), and Klaassen (2004) provides a framework to investigate the net effect of depreciation and risk on exports. Real export revenue $(x)$ depends on real foreign income $(y)$, the real exchange rate $(q)$, and exchange risk $\left(h_{q}\right): x=x\left(y, q, h_{q}\right) . \quad$ Seasonally adjusted real export revenue $x$ is nominal export revenue in domestic currency deflated by the consumer price index (CPI). Foreign income $y$, the US industrial production index in the present application, would have a positive effect on normal exports. The real exchange rate $q$, the domestic currency price of the US dollar times the ratio of US to domestic CPIs, would have a positive effect on exports. Use of the real exchange rate is meant to eliminate potential ambiguity from adjusting price levels in the present long term study.

Bilateral export revenue is the monthly real figure with the US between January 1979 and October 2002, using a base year of 1995. All data come from the International Financial Statistics and Direction of Trade of the IMF and the AREMOS data set of Taiwan. The US accounts for a fair portion of exports from these Asian countries as reported in Table 1. Bilateral export revenue from the exchange rate country avoids asymmetric responses across exchange rates known to occur in aggregate data.

\section{[Table 1]}

Time series properties of variables are required to identify appropriate GARCH models. Table 2 reports preliminary statistics for log differences of exports and the real exchange rate, $\Delta l x_{t} \equiv 100 \times\left(\ln x_{t}-\right.$ $\left.\ln x_{t-1}\right)$ and $\Delta l q_{t} \equiv 100 \times\left(\ln q_{t}-\ln q_{t-1}\right) . \quad$ Every country has depreciation and export growth on average. 
Thailand has the highest mean export revenue growth at just over $1 \%$ and yearly depreciation of $0.2 \%$.

Indonesia has the highest annual depreciation at $0.4 \%$ and export growth of over $0.5 \%$. It appears that depreciation encourages exports, on average.

\section{[Table 2]}

Regarding unconditional risk measured by standard deviations, Indonesia has the most volatile exchange rate and export revenue while Japan has the least volatile exports and Taiwan the least volatile exchange rate. Volatility of export revenue is higher than for the exchange rate in every country. A general impression of volatility's impact on export revenue does not emerge from examining standard deviations and extreme values.

Skewness statistics reject symmetry of export revenue at the 5\% level for five countries, and for real exchange rates in every country except Singapore and Taiwan. Kurtosis statistics imply every series is leptokurtic with a fat tail. Jarque-Bera tests reject normality for all variables and countries, suggesting use of the Student-t distribution.

The Ljung-Box Q statistic tests for autocorrelation and the number of lags $(k)$ must be chosen. Tsay (2002) suggests $k=\ln (T)$ where $T=285=$ the number of observations, implying $k=5.65$ and autocorrelation tests are run to 6 lags. Ljung-Box statistics indicate autocorrelations in export revenue for every country but none for the exchange rate in Japan, Korea, and Singapore. Ljung-Box statistics for squared variables suggest time varying variance in every country except Japan. An ARMA process for mean and variance equations captures the dynamic structure. Valid inference in GARCH models requires stationarity. After selecting lag lengths by the AIC criterion, the Augmented Dickey-Fuller 
(ADF) test shows that $\Delta l x_{t}$ and $\Delta l q_{t}$ are individually stationary $\mathrm{I}(0)$ series at the $5 \%$ level.

Univariate $\operatorname{GARCH}(1,1)$ estimates identify properties of changing variance. There are higher order autocorrelations for the two series in most countries and ARMA processes for the two mean equations generate white noise residuals. Tables 3 and 4 report estimates of univariate GARCH models under t-distributions.

\section{[Table 3] [Table 4]}

Ljung-Box $\mathrm{Q}(k)$ statistics for standardized residuals $\varepsilon_{x, t}$ show no autocorrelations up to 6 lags in Table 3, suggesting an AR(2) process for Indonesia, Japan, Korea, Malaysia, Philippines, Singapore, and Taiwan. For Thailand an AR(5) obtains white noise with an insignificant AR(3) term. For the variance equation, a GARCH(1,1) process for Indonesia, Philippines, Singapore and Thailand, and a more parsimonious ARCH(1) model for Japan, Korea, Malaysia and Taiwan capture heteroskedasticity as evidenced by the low Ljung-Box statistics for squared standardized residuals $Q^{2}(k)$ up to 6 lags. All parameters in the variance equations are positive, and $\alpha_{1}+\alpha_{2}<1$, suggesting $\Delta l x_{t}$ has a stable time-varying variance process in every country. Coefficients of the degrees of freedom $v$ in Table 5 are significant, implying it is appropriate to use the Student t-distribution.

As a prior examination, the standard $\operatorname{GARCH}(1,1)$ model performs adequately for Japan, Malaysia, Singapore, and Taiwan. It may not be surprising that unstable variance processes emerge in Indonesia, Korea, the Philippines, and Thailand because the Asian crisis that began in Thailand during July 1997 increased exchange market volatility immediately. The Philippines experienced another volatile period from 1983 through 1984. Structural breaks may bias upward GARCH estimates of 
persistence in variance, vitiating the use of GARCH to estimate the mean equation. Perron $(1989,1997)$ suggests identifying break points by examining data and using dummy variables to capture shifts in mean or variance processes. Figure 1 shows time plots of the four exchange rates, marking the break dates.

[Figure 1]

One time shocks appear as a single pulse in the depreciation series and as a mean shift in volatility. Dummy variables enter the mean equation for Indonesia and Thailand and variance equations for Korea and the Philippines to capture their particular patterns. In the mean equation, the two dummies for Indonesia are $D_{1}=1$ for $t=1983: 4, D_{2}=1$ for $t=1986: 9$, and 0 otherwise; for Thailand, $D_{1}=1$ for $t=$ 1981:7, $\mathrm{D}_{2}=1$ for $\mathrm{t}=1984: 11$, and 0 otherwise. $\quad$ In the variance equation, for Indonesia dummies are $\mathrm{D}_{1}$ $=1$ for $\mathrm{t} \geq 1997: 7$, and 0 otherwise; for Korea $\mathrm{D}_{1}=1$ for $\mathrm{t} \geq 1997: 7$, and 0 otherwise; for the Philippines $\mathrm{D}_{1}=1$ for 1983:1 $\leq \mathrm{t} \leq 1984: 12, \mathrm{D}_{2}=1$ for $\mathrm{t} \geq 1997: 7$, and 0 otherwise; and for Thailand $D_{1}=1$ for $t \geq 1997: 7$ and 0 otherwise.

Low Ljung-Box $\mathrm{Q}(k)$ statistics up to 6 lags for standardized residuals of $\Delta l q_{t}$ in Table 4 suggest an AR(1) for Malaysia, the Philippines, and Taiwan; an MA(1) for Indonesia and Thailand; an $\operatorname{ARMA}(1,1)$ for Korea; and a constant term for Japan and Singapore are adequate to pick up autocorrelations. All coefficients of dummy variables in the mean and variance equations are positive with appropriate break dates. Low $\mathrm{Q}^{2}(k)$ statistics for squared standardized residuals imply conditional heteroskedasticity has been eliminated. All variance processes for $\Delta l q_{t}$ are positive and convergent.

\section{An empirical bivariate GARCH-M model}

Properties of the time varying variance in export revenue and the exchange rate $\left(\Delta l x_{t}\right.$ and $\left.\Delta l q_{t}\right)$ 
suggest an unrestricted bivariate GARCH model to analyze the net effect of depreciation and risk. The following eclectic GARCH-M model provides a framework to investigate the net effect,

$$
\begin{gathered}
\Delta l x_{t}=a_{0}+\sum_{i=1}^{5} a_{i} \cdot \Delta l x_{t-i}+b \cdot \Delta l y_{t-1}+c \cdot \Delta l q_{t-1}+d \cdot h_{q, t-1}+\varepsilon_{x, t} \\
\Delta l q_{t}=e_{0}+e_{1} \cdot \Delta l q_{t-1}+\sum_{i=1}^{2} z_{i} \cdot D_{i}+m_{q} \cdot \varepsilon_{q, t-1}+\varepsilon_{q, t} \\
\varepsilon_{t}=\left(\varepsilon_{x, t}, \varepsilon_{q, t}\right)^{\prime} \quad \varepsilon_{t} \mid \Psi_{t-1} \sim \text { Student }-t(v) \\
H_{t}=\left(\begin{array}{ll}
h_{x, t} & h_{x q, t} \\
h_{x q, t} & h_{q, t}
\end{array}\right) \\
h_{x, t}=\alpha_{0}+\alpha_{1} \cdot \varepsilon_{x, t-1}^{2}+\alpha_{2} \cdot h_{x, t-1} \\
h_{q, t}=\beta_{0}+\beta_{1} \cdot \varepsilon_{q, t-1}^{2}+\beta_{2} \cdot h_{q, t-1}+\sum_{i=1}^{2} \gamma_{i} \cdot D_{i} \\
h_{x q, t}=\rho_{x q} \cdot \sqrt{h_{x, t} \cdot h_{q, t}}
\end{gathered}
$$

where $\Delta l y_{t} \equiv 100 \times\left(\ln y_{t}-\ln y_{t-1}\right) . \quad$ ARMA components pick up serial dependence to ensure $\varepsilon_{x, t}$ and $\varepsilon_{q, t}$ are white noise. The error series $\varepsilon_{t}$, conditional on information set $\Psi_{t-1}$ available at time $t-1$, is assumed to follow a bivariate Student-t distribution with $v$ degrees of freedom. The dummy variable $D_{i}$ captures the single pulse or mean shift of extraordinary exchange rate changes. Conditional variances are $h_{x, t}$ and $h_{q, t}$, and $h_{x q, t}$ is the covariance. The correlation coefficient of $\Delta l x_{t}$ and $\Delta l q_{t}$ is $\rho_{x q}$. The presence of $h_{q, t}$ in (1) makes the system (1) - (7) a bivariate GARCH(1,1)-M model. Conditions $\alpha_{i}>0, \beta_{i}>0$ and $\gamma_{i}>0$ ensure positive conditional variance. Restrictions $\alpha_{1}+\alpha_{2}<1$ and $\beta_{1}+\beta_{2}<1$ maintain stable variance. If $\alpha_{2}=0$ or $\beta_{2}=0$, the variance equation reduces to an $\mathrm{ARCH}(1)$ specification. The constant correlation specification suggested by Bollerslev (1990) in (7) reduces the number of parameters and increases degrees of freedom. Parameters of the system (1)-(7) are estimated 
by maximizing the log-likelihood function of the bivariate Student-t distribution,

$$
\ln L_{t}=\ln \Gamma\left(\frac{v+2}{2}\right)-\ln (v-2)-\ln \Gamma\left(\frac{v}{2}\right)-0.5 \ln \left|H_{t}\right|-\left(\frac{v+2}{2}\right) \cdot \ln \left(1+\frac{\varepsilon_{t}^{\prime} H_{t}^{-1} \varepsilon_{t}}{v-2}\right)
$$

where $\Gamma$ is a Gamma function.

The model focuses on the effects of exchange rate movements on export revenue in equilibrium, and the reduced form equation includes depreciation and risk as well as the rate of change of foreign income as explanatory variables. The significance and sign of the estimated parameter $c$ in (1) is a straightforward test of the relationship between exports and depreciation, a positive $c$ implying a positive effect. A negative coefficient $d$ in (1) would imply a negative risk effect.

Table 5 reports estimated coefficients and asymptotic standard errors. All estimates of ARMA components and dummy variables in mean equations (1) and (2) are significant and parameters in the two variance equations are positive. Every country has time varying variances for exports and exchange rates supporting the bivariate GARCH model. The significance of $\gamma_{1}$ and $\gamma_{2}$ in (6) confirms the use of dummy variables for structural breaks. Volatility persistence of export revenue varies from 0.156 for Taiwan to 0.985 for Indonesia, and for the exchange rate from 0.459 in Taiwan to 0.968 in Malaysia. The two variance processes converge. Estimated conditional correlation coefficients between $\Delta l x_{t}$ and $\Delta l q_{t}$ are positive for Indonesia, Japan, and Philippines. The estimated conditional correlation coefficients are close to the unconditional coefficients from the two series in Table 2: 0.221 for Indonesia, 0.213 for Japan, 0.170 for Korea, 0.064 for Malaysia, 0.303 for Philippines, 0.102 for Singapore, -0.010 for Taiwan, and 0.117 for Thailand. Joint estimates of the degrees of freedom of the t-distribution are 
significant, and the hypothesis of the standardized Student-t distribution is not rejected. Bivariate Ljung-Box $Q_{2}(k)$ statistics (Hosking, 1980) for standardized residuals and squared residuals do not detect remaining autocorrelation or conditional heteroskedasticity. The bivariate GARCH-M model (1)-(7) is adequate for each country.

[Table 5]

The marginal effect of US manufacturing income on exports in Table 5 is positive for Malaysia, the Philippines, and Taiwan. There is a general positive trend in US income, especially during the middle of the period. The significant US income elasticities range from 1.7 to 2.2. The different responses of export revenue reflect different degrees of dependence on US importers.

Depreciation has the expected positive effect on exports except in Malaysia and Singapore. Abeysinghe and Yeok (1998) find that appreciation does not diminish Singapore's exports due to their high import content, lower import prices evidently lowering the cost of export production. The exchange rate effect ranges from 0.289 for Japan to 0.979 for Thailand. The near zero mean and negatively skewed Japanese exchange rate changes implies monthly yen appreciation occurs more often during the period.

Exchange risk has negative effects in Japan, Singapore, and Taiwan. The negative risk effect in Taiwan is consistent with Fang and Thompson (2004). Klaassen (2004) finds no risk effect at all on bilateral US export revenue from the other G7 countries, arguing that the exchange rate risk is too constant in developed countries to uncover any effect. Klaassen suggests examining developing countries with their more volatile exchange rates, and three of the eight Asian countries in the present study reveal risk 
effects on bilateral exports.

The likelihood ratio statistic LR(1) with a $\chi^{2}$ distribution and one degree of freedom tests the validity of the restriction $c+d=0$, whether the total influence of depreciation and risk on exports is zero. Tests for Indonesia, Korea, the Philippines, and Thailand reject the hypothesis. These four countries have relatively strong positive depreciation effects and insignificant positive or negative risk effects. The other four countries have insignificant depreciation effects (Malaysia and Singapore), insignificant risk effects (Malaysia), or negative risk effects (Japan, Singapore, Taiwan).

Risk effects can contribute to the net exchange rate effect. In Singapore, depreciation has no effect but exchange risk has a large negative effect. In Taiwan, a large negative risk effect offsets the positive depreciation effect. In Japan, there is a dominating risk effect associated with the typically appreciating yen. In Malaysia, neither depreciation nor exchange risk have any effect, perhaps evidence that exporters do business in foreign currencies and local factor payments are a small share of their total costs. In the other four countries, Indonesia, Korea, the Philippines, and Thailand, risk effects are not significant.

\section{Quantitative analysis of depreciation and risk}

The mean percentage change in US output $\Delta l y_{t}$ is $0.19 \%$. For the eight countries as a group, the average of these eight marginal effects of 1.2 implies an average monthly impact of $0.19 \% \times 1.2=$ $0.23 \%$. The largest percentage change in US output over the period was $2.1 \%$, implying growth of $2.5 \%$ in export revenue for the average sample country. The largest monthly decline in US output of $2.5 \%$ implies a decrease of $-3.0 \%$ in export revenue. The average yearly impact is $0.23 \% \mathrm{x} 12=2.8 \%$. The 
implied individual yearly impacts are 5.0\% for Malaysia, 4.8\% for Taiwan, 3.8\% for the Philippines, $2.0 \%$ for Singapore, $1.9 \%$ for Thailand, $1.6 \%$ for Indonesia, $1.4 \%$ for Korea, and 1.1\% for Japan. These Asian exporters certainly notice US business cycles. The standard deviation of US income $0.64 \%$ implies most observations of $\Delta l y_{t}$ fall between $-0.45 \%$ and $0.83 \%$ with associated monthly impacts on exports ranging from $-0.54 \%$ to $0.99 \%$.

Depreciation increases export revenue except for Malaysia and Singapore. Using the means of exchange rate changes in Table 2 and estimated coefficients in Table 5, monthly impacts on exports are $0.23 \%$ for Indonesia, $0.20 \%$ for Thailand, $0.17 \%$ for the Philippines, $0.06 \%$ for Korea, $0.02 \%$ for Taiwan, and $0.01 \%$ for Japan. Including the insignificant coefficients, effects are $0.04 \%$ for Malaysia and $0.02 \%$ for Singapore. The standard deviation of $\Delta l q_{t}$ in Table 2 implies that the average range of potential monthly impacts on export revenue (mean $\Delta l q_{t} \pm$ std dev) $\times \mathrm{c}$ are $(-3.7 \%, 4.2 \%)$ for Indonesia, $(-2.4 \%$, $2.8 \%)$ for Thailand, $(-2.8 \%, 3.1 \%)$ for the Philippines, $(-1.6,1.7 \%)$ for Korea, $(-0.28 \%, 0.36 \%)$ for Malaysia, $(-0.35 \%, 0.39 \%)$ for Singapore, $(-0.72 \%, 0.77 \%)$ for Taiwan, and $(-0.91 \%, 0.94 \%)$ for Japan. Typical impacts are less than 1\% for Japan, Malaysia, Singapore, and Taiwan. Athukorala and Menon (1994) and Abeysinghe and Yeok (1998) discuss the weak links between appreciation and exports in Japan and Singapore.

Regarding the size of the exchange risk impact, the means of conditional variance $h_{q, t}$ in the bivariate GARCH-M model are 31.2 for Indonesia, 10.7 for Japan, 8.62 for Korea, 4.56 for Malaysia, 7.21 for the Philippines, 2.55 for Singapore, 2.65 for Taiwan, and 3.54 for Thailand. The monthly impacts of risk on export revenue (mean of $h_{q, t} \times d$ ) are $-2.5 \%$ for Japan, $-0.65 \%$ for Singapore, $-0.37 \%$ for 
Taiwan. Including the insignificant risk coefficients, risk impacts are $-0.0 \%$ for Indonesia, $-0.09 \%$ for Malaysia, $0.15 \%$ for Korea, $0.19 \%$ for the Philippines, and $-0.10 \%$ for Thailand. Standard deviations of $h_{q, t}$ are 3.9 for Japan, 1.8 for Singapore, 3.0 for Taiwan, 9.9 for Thailand, 18 for Malaysia, 104 for Indonesia, 36 for Korea, and 20 for the Philippines, implying ranges of monthly influences on export revenue (mean of $h_{q, t} \pm$ standard deviation) $\times d$ of $(-3.4 \%,-1.6 \%)$ for Japan, $(-0.2 \%,-1.1 \%)$ for Singapore, $(-0.8 \%, 0.1 \%)$ for Taiwan, and $(-0.4 \%, 0.2 \%)$ for Thailand, $(-0.4 \%, 0.3 \%)$ for Malaysia, $(-0.05 \%, 0.03 \%)$ for Indonesia, $(-0.5 \%, 0.8 \%)$ for Korea, and $(-0.3 \%, 0.7 \%)$ for the Philippines. The very large effect in Japan suggests risk has a larger impact during appreciation, more common in Japan on a monthly basis.

The net quantitative impacts are summarized in Table 6 with zeros for insignificant effects. The negative impact of risk overcomes the positive impact of depreciation for Taiwan and Japan (where appreciation is the rule). The positive impact of depreciation holds with on impact of exchange risk in Indonesia, Korea, the Philippines, and Thailand. Singapore exhibits no effects of depreciation but a large negative risk effect. In Malaysia there are no impacts of depreciation or risk.

\section{[Table 6]}

The size of the risk estimate and the standard deviation of time varying exchange rate volatility appear related. Indonesia, Korea, Malaysia, the Philippines, and Thailand have high standard deviations of conditional exchange rate variance, ranging from 10 in Thailand to 104 in Indonesia. These same countries exhibit small risk estimates, ranging from -0.03 in Thailand to 0.03 in the Philippines. In contrast, lower conditional variances ranging from $(1.75,3.03,3.87)$ in (Singapore, Taiwan, Japan) are 
associated with higher negative risk estimates $(-0.25,-0.23,-0.14)$. Exporters facing volatile exchange rates apparently hedge or aggressively manage exchange risk, resulting in a small risk effect. In Singapore and Taiwan, low volatility lulls exporters into neglecting risk and leads to a significant negative risk effect. In Japan, appreciation is associated with very large risk effects, as US importers must be more sensitive to exchange risk with rising dollar prices.

An experiment to examine the net effect of depreciation uses a simulated trend of "fundamental" export revenue based on initial export revenue combined with the coefficients from Table 5 except for the exchange rate and its risk. Figure 2 displays time plots for the actual and simulated series, as well as the difference between them, and Table 7 reports statistics of the differences.

\section{[Table 7] [Figure 2]}

Means of the difference are close to zero. In Taiwan, insignificant Ljung-Box Q statistics of the difference and the squared difference up to 6 lags suggest the difference has zero covariance and constant variance at the 5\% level. The conclusion is that the exchange rate and its risk add noise to the fundamentals of export revenue, a conclusion reached by Fang and Thompson (2004) with aggregate data. For Indonesia, Korea, the Philippines, and Thailand, the significant autocorrelation or time varying variance of the difference suggests the exchange rate and risk are important in explaining export revenue. Omission of the two variables results in significant Ljung-Box Q statistics, corresponding to the significant LR statistics in Table 5. For Japan, Malaysia, and Singapore, the Ljung-Box statistic is significant for the difference and the squared difference but insignificant LR statistics in Table 5 suggest depreciation has a weak effect. 


\section{Exchange rate behavior before and after the crisis}

Instability of the exchange rates triggered by the Asian crisis in Indonesia, Korea, the Philippines, and Thailand evokes the issue of switches in exchange rate regimes. Hallett and Anthony (1997) and Frömmel and Menkhoff (2001) show that different regimes are characterized by different exchange rate distributions that could lead to different outcomes in the model. To help isolate the impact of the Asian crisis, depreciation rates before and after the crisis can be compared. The present sample is split into two periods at the crisis in June 1997 to compare the distributions of depreciation and risk, summarized in Table 8.

[Table 8]

The Asian crisis weakened the currencies substantially. Each country has higher mean depreciation and standard deviation after the crisis. The largest depreciation and appreciation (lowest minimum) also occur after the crisis for all countries except Japan and the Philippines.

Indonesia, Korea, the Philippines, and Thailand show sharp drops in skewness, kurtosis, and Jarque-Bera normality test statistics after the crisis. The distribution of depreciation becomes less asymmetric and less centralized around the mean in these countries, but non-normally distributed properties remain the same at the 5\% level of significance. For these four countries, the exchange rate system becomes less fragile and market volatility increases. The high kurtosis and positive skewness in Korea after the crisis may indicate more active exchange market intervention.

Japan, Malaysia, Singapore, and Taiwan have stable GARCH processes of their exchange rates individually during the sample period, and show different responses to the crisis. After the crisis, 
negative skewness increases in Japan and Singapore, positive skewness changes to negative in Malaysia, and negative skewness becomes positive in Taiwan. Kurtosis statistics are significant both before and after the crisis. Kurtosis falls in Singapore, similar to the four countries mentioned above, but increases in Japan, Malaysia, and Taiwan. The statistics of the Jarque-Bera normality test increase for Japan and Malaysia, and decrease for Singapore and Taiwan.

Hallett and Anthony (1997) point out that semi-fixed exchange rates show higher kurtosis, and are more stable but also more fragile. In the present data, Indonesia, Korea, the Philippines, and Thailand have high kurtosis statistics before the crisis when their currencies suffered seriously as captured by the divergent GARCH processes.

The kurtosis statistics in Table 8 tend to converge across the eight Asian countries after the crisis, ranging from 4.7 to 15.3. The present figures can be compared with those of Hallett-Anthony, where the kurtosis of the five EMS currencies ranges from 4.8 to 7.6 before the crisis, and from 8.8 to 59.4 after the crisis. EMS currencies show increased fragility after the crisis, while the Asian currencies have shown increased robustness. Standard deviations range from 1.25 to 3.18 before the crisis and increase to a range of 2.06 to 12.7 after the crisis. In Hallett-Anthony, the standard deviations for the five EMS currencies are much lower, ranging from 0.05 to 0.81 before and 0.02 to 0.30 after the EMS.

Frömmel and Menkhoff (2001) also find decreasing conditional variance for five of six European Monetary System exchange rates. The present paper finds increased volatility of Asian exchange rates during recent years. The present model cannot be estimated separately in the two sub-periods because the sample size of 64 after the crisis is small for the bivariate GARCH-M model and too few degrees of 
freedom make estimation inefficient.

Klaassen (2004) makes the point that the study of exchange risk requires data on developing countries with high exchange rate risk as in the present sample. Klaasen advocates the use of forward looking risk, a potential topic for the present methodology.

The 1997 Asian crisis certainly affected these bilateral exchange rates. Influences include a higher depreciation rate and standard deviation for all countries, and lower skewness and kurtosis for most. The kurtosis and the Jarque-Bera test are significant in the full sample as well as the two periods. The crisis changed the size of each statistic but not its significance, affecting exchange rate behavior inside the regime but not switching regimes. The distribution properties of depreciation are stable across sub-periods and the model estimation is consistent. The system of semi-fixed Asian exchange rates is characterized by significant kurtosis, allowing Asia to expand exports by keeping its currencies cheap. This mechanism that can persist as long as Asia continues to supply investment funds to the US.

\section{Conclusion}

Depreciation typically stimulated bilateral export revenue across eight Asian economies during the 1980s and 1990s, ignoring exchange risk. In the present simultaneous model including the effect of time varying risk, the net effects are less uniform.

Exchange risk has negative impacts on export revenue for three of the countries that tend to cancel the positive effects. The net effect of the exchange rate on export revenue is significant for only half the countries, weak for three, and adds noise for one. A large negative risk effect in Japan is associated with monthly yen appreciation. 
These results have policy implications for a government considering policy to depreciate its currency and stimulate exports. There is little guarantee such intervention will be successful. Exporters and foreign importers react differently to the exchange rate, and exchange risk typically affects export revenue. Conditions vary across countries and each has to be evaluated on its own merit. Policymakers should carefully consider exchange market intervention since associated exchange risk may offset any positive effects. 
Table 1. US share of total exports

\begin{tabular}{cl}
\hline Country & Ratio \\
\hline Indonesia & $14.5 \%$ \\
Japan & $29.2 \%$ \\
Korea & $21.3 \%$ \\
Malaysia & $21.4 \%$ \\
Philippines & $27.8 \%$ \\
Singapore & $15.3 \%$ \\
Taiwan & $20.5 \%$ \\
Thailand & $19.6 \%$ \\
\hline
\end{tabular}

The data are from the Direction of Trade of the IMF, exports to the US/total exports. 
Table 2. Preliminary statistics for exports and the exchange rate

\begin{tabular}{|c|c|c|c|c|c|c|c|c|}
\hline & \multicolumn{2}{|c|}{ Indonesia } & \multicolumn{2}{|c|}{ Japan } & \multicolumn{2}{|c|}{ Korea } & \multicolumn{2}{|c|}{ Malaysia } \\
\hline & $\Delta l x_{t}$ & $\Delta l q_{t}$ & $\Delta l x_{t}$ & $\Delta l q_{t}$ & $\Delta l x_{t}$ & $\Delta l q_{t}$ & $\Delta l x_{t}$ & $\Delta l q_{t}$ \\
\hline Sample size & 285 & 285 & 285 & 285 & 285 & 285 & 285 & 285 \\
\hline Mean & 0.457 & 0.381 & 0.270 & 0.044 & 0.574 & 0.128 & 0.802 & 0.258 \\
\hline $\mathrm{SD}$ & 25.757 & 6.482 & 6.621 & 3.195 & 12.335 & 3.326 & 12.583 & 2.110 \\
\hline Maximum & 109.936 & 61.263 & 25.981 & 11.348 & 47.486 & 34.978 & 43.994 & 14.890 \\
\hline Minimum & -123.966 & -26.369 & -19.369 & -14.124 & -46.113 & -16.268 & -72.185 & -15.417 \\
\hline \multirow[t]{2}{*}{ Skewness } & $-0.260 *$ & $3.371 *$ & $0.400 *$ & $-0.637^{*}$ & $-0.281^{*}$ & $4.390 *$ & $-0.524^{*}$ & $0.339 *$ \\
\hline & $(0.145)$ & $(0.145)$ & $(0.145)$ & $(0.145)$ & $(0.145)$ & $(0.145)$ & $(0.145)$ & $(0.145)$ \\
\hline \multirow[t]{2}{*}{ Kurtosis } & $6.816^{*}$ & $36.013^{*}$ & $4.103^{*}$ & $4.542^{*}$ & $4.832^{*}$ & $51.646^{*}$ & $7.404 *$ & $25.520 *$ \\
\hline & $(0.290)$ & $(0.290)$ & $(0.290)$ & $(0.290)$ & $(0.290)$ & $(0.290)$ & $(0.291)$ & $(0.291)$ \\
\hline J-B N & $176.181^{*}$ & $13481.97 *$ & $22.048 *$ & $47.489 *$ & $43.571 *$ & $29016.97 *$ & $242.537 *$ & $6006.54^{*}$ \\
\hline$Q(3)$ & $51.166^{*}$ & $13.308^{*}$ & $41.884^{*}$ & 5.079 & $63.502 *$ & 3.150 & $102.383^{*}$ & $12.911 *$ \\
\hline$Q(6)$ & $56.675^{*}$ & $28.656^{*}$ & $58.403^{*}$ & 6.417 & $78.855^{*}$ & 8.609 & $104.029 *$ & $14.034 *$ \\
\hline$Q^{2}(3)$ & $49.971 *$ & $40.657^{*}$ & 5.996 & 4.583 & $69.386^{*}$ & $48.186^{*}$ & $35.990 *$ & $136.061^{*}$ \\
\hline$Q^{2}(6)$ & $50.069 *$ & $59.075^{*}$ & 8.962 & 5.942 & $74.083^{*}$ & $49.773 *$ & $36.499 *$ & $183.136^{*}$ \\
\hline $\mathrm{ADF}(\mathrm{m})$ & $-19.35(1)^{*}$ & $-14.14(0)^{*}$ & $-4.53(11)^{*}$ & $-15.61(0)^{*}$ & $-18.65(1)^{*}$ & $-15.81(0)^{*}$ & $-31.44(0)^{*}$ & $-12.71(0)^{*}$ \\
\hline
\end{tabular}

\section{Philippines Singapore}

Taiwan

Thailand

\begin{tabular}{|c|c|c|c|c|c|c|c|c|}
\hline & $\Delta l x_{t}$ & $\Delta l q_{t}$ & $\Delta l x_{t}$ & $\Delta l q_{t}$ & $\Delta l x_{t}$ & $\Delta l q_{t}$ & $\Delta l x_{t}$ & $\Delta l q_{t}$ \\
\hline Sample size & 285 & 285 & 285 & 285 & 285 & 285 & 285 & 285 \\
\hline Mean & 0.637 & 0.191 & 0.530 & 0.093 & 0.277 & 0.048 & 1.012 & 0.205 \\
\hline $\mathrm{SD}$ & 9.786 & 3.373 & 11.148 & 1.618 & 9.037 & 1.586 & 11.581 & 2.633 \\
\hline Maximum & 37.414 & 23.133 & 52.260 & 6.518 & 37.534 & 8.643 & 48.387 & 16.295 \\
\hline Minimum & -34.924 & -9.373 & -42.250 & -7.434 & -26.102 & -6.964 & -43.718 & -15.911 \\
\hline \multirow[t]{2}{*}{ Skewness } & 0.019 & $2.226^{*}$ & 0.007 & -0.105 & $0.338^{*}$ & 0.115 & -0.163 & $1.851 *$ \\
\hline & $(0.145)$ & $(0.145)$ & $(0.145)$ & $(0.145)$ & $(0.145)$ & $(0.145)$ & $(0.145)$ & $(0.145)$ \\
\hline \multirow[t]{2}{*}{ Kurtosis } & $4.932^{*}$ & $15.532^{*}$ & $5.454^{*}$ & $6.084^{*}$ & $4.545^{*}$ & $7.840^{*}$ & $6.425^{*}$ & $23.706^{*}$ \\
\hline & $(0.290)$ & $(0.290)$ & $(0.290)$ & $(0.290)$ & $(0.290)$ & $(0.290)$ & $(0.290)$ & $(0.290)$ \\
\hline J-B N & $44.353 *$ & 2100.19* & $71.541 *$ & $113.464 *$ & 33.776* & $278.779 *$ & $140.566^{*}$ & $5253.81^{*}$ \\
\hline$Q(3)$ & $65.900 *$ & 3.369 & $69.318^{*}$ & 3.129 & 91.190* & 10.536 & $38.954^{*}$ & $23.518^{*}$ \\
\hline$Q(6)$ & $67.577^{*}$ & $10.704 * *$ & $70.550 *$ & 5.831 & $91.664 *$ & 18.774* & $59.53 *$ & $28.062 *$ \\
\hline$Q^{2}(3)$ & $28.571^{*}$ & $6.288 * *$ & $22.260^{*}$ & $38.972 *$ & $38.651^{*}$ & 5.506 & $56.782 *$ & $127.049^{*}$ \\
\hline$Q^{2}(6)$ & $31.639 *$ & $11.359 * *$ & $31.642 *$ & $78.897 *$ & $41.954 *$ & $7.573 * *$ & $125.793^{*}$ & $183.183^{*}$ \\
\hline $\mathrm{ADF}(\mathrm{m})$ & $-18.65(1)^{*}$ & $-17.90(0) *$ & $-19.15(1)^{*}$ & $-16.14(0) *$ & $-20.26(1)^{*}$ & $-14.20(0)^{*}$ & $-9.29(5)^{*}$ & $-12.61(0)^{*}$ \\
\hline
\end{tabular}

SD represents standard deviation; J-B N denotes Jarque-Bera normality test; $Q(k)$ and $Q^{2}(k)$ are Ljung-Box statistics for level and squared terms for autocorrelations up to k lags; $\mathrm{ADF}(\mathrm{m})$ is the Augmented Dickey-Fuller unit root test with lags $m$ selected by the AIC criterion; * and ** denote significance at the $5 \%$ and $10 \%$ level, respectively. 
Table 3. Estimates for univariate GARCH models for $\Delta l x_{t}$

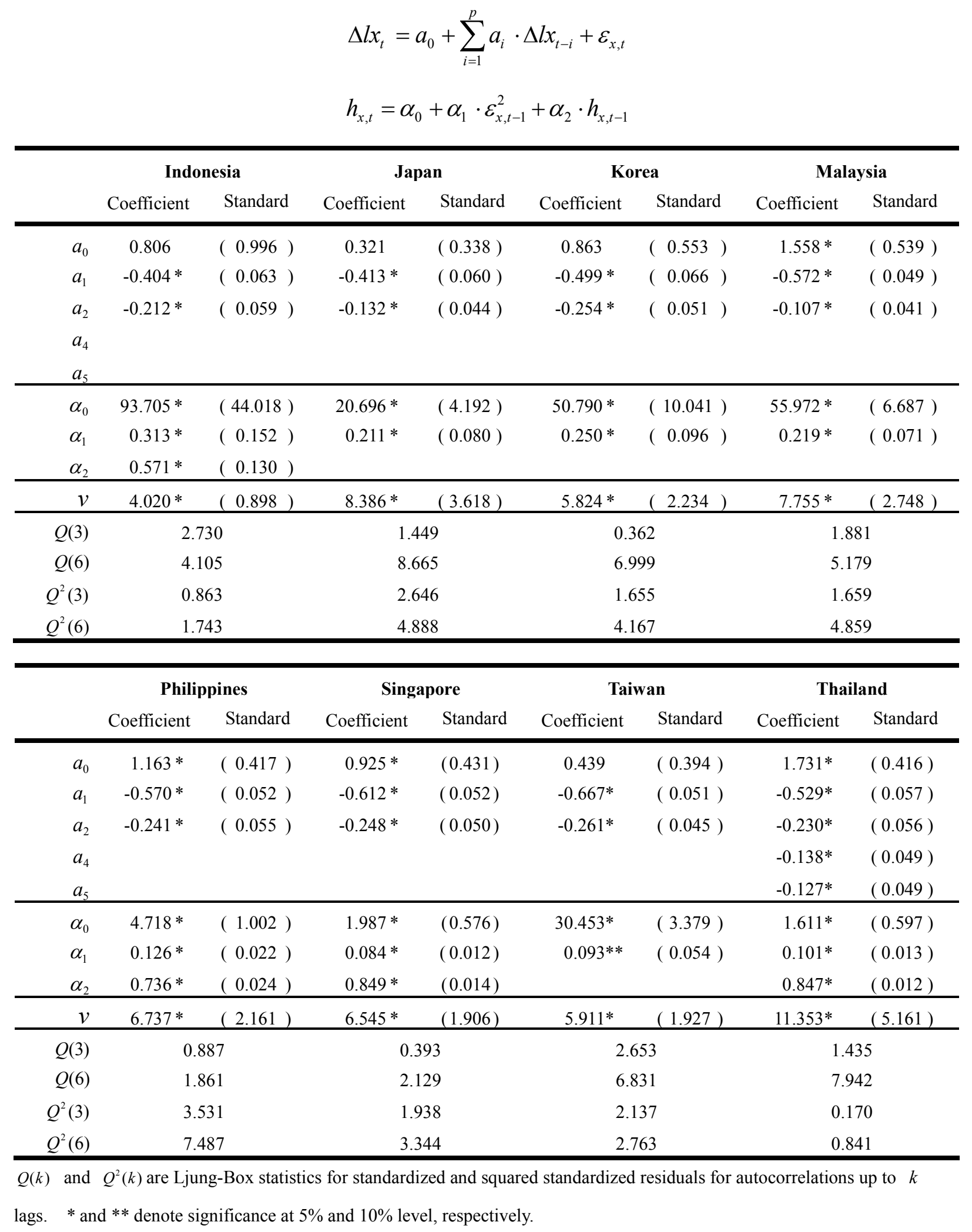


Table 4. Estimates for univariate GARCH models for $\Delta l q_{t}$

\begin{tabular}{|c|c|c|c|c|c|c|c|c|}
\hline & \multicolumn{2}{|c|}{ Indonesia } & \multicolumn{2}{|c|}{ Japan } & \multicolumn{2}{|c|}{ Korea } & \multicolumn{2}{|c|}{ Malaysia } \\
\hline & Coefficient & Standard & Coefficient & Standard & Coefficient & Standard & Coefficient & Standard \\
\hline$e_{0}$ & $0.092 * *$ & $(0.049)$ & 0.246 & $(0.2185)$ & 0.007 & $(0.012)$ & $0.089 * *$ & $(0.050)$ \\
\hline$e_{1}$ & & & & & $0.841 *$ & $(0.015)$ & $0.223 *$ & $(0.064)$ \\
\hline$m_{q}$ & $0.135 *$ & $(0.060)$ & & & $-0.694 *$ & $(0.024)$ & & \\
\hline$z_{1}$ & $30.458 *$ & $(2.730)$ & & & & & & \\
\hline$z_{2}$ & $21.548 *$ & $(8.043)$ & & & & & & \\
\hline$\beta_{0}$ & $0.136 *$ & $(0.026)$ & $4.547 *$ & $(1.125)$ & $0.185 *$ & $(0.053)$ & $0.138 *$ & $(0.030)$ \\
\hline$\beta_{1}$ & $0.147 *$ & $(0.046)$ & $0.113 *$ & $(0.037)$ & $0.178 *$ & $(0.052)$ & $0.255 *$ & $(0.048)$ \\
\hline$\beta_{2}$ & $0.261 *$ & $(0.068)$ & $0.240 *$ & $(0.121)$ & $0.283 *$ & $(0.087)$ & $0.391 *$ & $(0.048)$ \\
\hline$\gamma_{1}$ & $9.992 *$ & $(4.065)$ & & & $2.154 *$ & $(0.999)$ & & \\
\hline \multicolumn{9}{|l|}{$\gamma_{2}$} \\
\hline$v$ & $2.612 *$ & $(0.338)$ & $7.380 *$ & $(2.863)$ & $3.093 *$ & $(0.560)$ & $3.089 *$ & $(0.546)$ \\
\hline$Q(3)$ & \multicolumn{2}{|c|}{0.749} & \multicolumn{2}{|c|}{5.432} & \multicolumn{2}{|c|}{0.574} & \multicolumn{2}{|c|}{1.680} \\
\hline$Q(6)$ & \multicolumn{2}{|c|}{1.207} & \multicolumn{2}{|c|}{6.995} & \multicolumn{2}{|c|}{3.629} & \multicolumn{2}{|c|}{4.818} \\
\hline$Q^{2}(3)$ & \multicolumn{2}{|c|}{0.112} & \multicolumn{2}{|c|}{1.093} & \multicolumn{2}{|c|}{0.078} & \multicolumn{2}{|c|}{0.827} \\
\hline \multirow[t]{3}{*}{$Q^{2}(6)$} & \multicolumn{2}{|c|}{0.163} & \multicolumn{2}{|c|}{3.445} & \multicolumn{2}{|c|}{0.140} & \multicolumn{2}{|c|}{1.103} \\
\hline & \multicolumn{2}{|c|}{ Philippines } & \multicolumn{2}{|c|}{ Singapore } & \multicolumn{2}{|c|}{ Taiwan } & \multicolumn{2}{|c|}{ Thailand } \\
\hline & Coefficient & Standard & Coefficient & Standard & Coefficient & Standard & Coefficient & Standard \\
\hline$e_{0}$ & -0.061 & $(0.062)$ & 0.025 & $(0.065)$ & 0.059 & $(0.069)$ & -0.039 & $(0.058)$ \\
\hline$e_{1}$ & $0.191 *$ & $(0.060)$ & & & $0.253 *$ & $(0.060)$ & & \\
\hline$m_{q}$ & & & & & & & $0.229 *$ & $(0.060)$ \\
\hline$z_{1}$ & & & & & & & $6.235^{*}$ & $(1.683)$ \\
\hline$z_{2}$ & & & & & & & $15.126^{*}$ & $(1.481)$ \\
\hline$\beta_{0}$ & $0.212 *$ & $(0.055)$ & $0.228 *$ & $(0.082)$ & $0.753 *$ & $(0.106)$ & $0.071 *$ & $(0.014)$ \\
\hline$\beta_{1}$ & $0.210 *$ & $(0.055)$ & $0.095 *$ & $(0.043)$ & $0.211 *$ & $(0.075)$ & $0.069 *$ & $(0.018)$ \\
\hline$\beta_{2}$ & $0.219 *$ & $(0.062)$ & $0.712 *$ & $(0.072)$ & & & $0.708 *$ & $(0.032)$ \\
\hline$\gamma_{1}$ & $4.541 * *$ & $(2.423)$ & & & & & $0.386^{*}$ & $(0.193)$ \\
\hline$\gamma_{2}$ & $1.538 *$ & $(0.767)$ & & & & & & \\
\hline$v$ & $2.151 *$ & $(0.270)$ & $5.579 *$ & $(1.490)$ & $3.617 *$ & $(0.648)$ & $3.641 *$ & $(0.503)$ \\
\hline$Q(3)$ & 1.5 & & & & & & & \\
\hline$Q(6)$ & 7.2 & & & & & & & \\
\hline$Q^{2}(3)$ & 0.2 & & & & & & & \\
\hline$Q^{2}(6)$ & 0.3 & & & & & & & \\
\hline
\end{tabular}

$Q(k)$ and $Q^{2}(k)$ are Ljung-Box statistics for standardized and squared standardized residuals for autocorrelations up to $k$ lags. $*$ and $* *$ denote significance at $5 \%$ and $10 \%$ level, respectively. 
Table 5. Estimates for bivariate GARCH-M model



$Q_{2}(k)$ and $Q_{2}^{2}(k)$ are the bivariate Ljung-Box statistics (Hosking, 1980) of the standardized and squared standardized residuals for autocorrelations up to $k$ lags. $L R(1)$ is the likelihood ratio statistic following a $\chi^{2}$ distribution with one degree of freedom that tests $c+d=0$, whose critical values of $5 \%$ significant level is 3.84 . * and ** denote significance at $5 \%$ and $10 \%$ level, respectively. 
Table 6. Summary of estimated monthly impact of depreciation and exchange risk

\begin{tabular}{|c|c|c|c|}
\hline Country & Depreciation effect & Exchange risk effect & Net effect \\
\hline Indonesia & .23 & 0 & .23 \\
\hline Japan & $.01^{*}$ & -.25 & -.24 \\
\hline Korea & .06 & .15 & .21 \\
\hline Malaysia & 0 & 0 & 0 \\
\hline Philippines & .17 & 0 & .17 \\
\hline Singapore & 0 & -.65 & -.63 \\
\hline Taiwan & .02 & -.37 & -.35 \\
\hline Thailand & .20 & 0 & .20 \\
\hline
\end{tabular}

*appreciating currency most months 
Table 7. Preliminary statistics of difference between actual and

\section{fundamental exports}

\begin{tabular}{ccccccccc}
\hline & Indonesia & Japan & Korea & Malaysia & Philippines & Singapore & Taiwan & Thailand \\
\hline Mean & 0.001 & -0.025 & 0.001 & -0.002 & 0.002 & -0.006 & -0.003 & 0.004 \\
Max & 0.714 & 0.196 & 0.441 & 0.307 & 0.287 & 0.372 & 0.196 & 0.348 \\
Min & -1.295 & -0.199 & -0.360 & -0.537 & -0.291 & -0.368 & -0.218 & -0.464 \\
SD & 0.232 & 0.061 & 0.106 & 0.102 & 0.083 & 0.093 & 0.070 & 0.104 \\
$Q(3)$ & $7.338^{* *}$ & 1.482 & 0.038 & 2.454 & 3.605 & 4.549 & 4.589 & $14.520^{*}$ \\
$Q(6)$ & 10.493 & $11.380^{* *}$ & 6.942 & 5.008 & 6.225 & 6.550 & 8.909 & $15.637^{*}$ \\
$Q^{2}(3)$ & $9.973^{*}$ & $9.171^{*}$ & $15.869^{*}$ & $10.000^{*}$ & $19.692^{*}$ & $17.766^{*}$ & 4.050 & $45.630^{*}$ \\
$Q^{2}(6)$ & 10.255 & $10.698^{* *}$ & $19.762^{*}$ & $13.001^{*}$ & $25.106^{*}$ & $40.087^{*}$ & 4.120 & $91.482^{*}$ \\
\hline
\end{tabular}

SD represents standard deviation; $Q(k)$ and $Q^{2}(k)$ are Ljung-Box statistics for the difference and squared difference for autocorrelations up to k lags; * and ${ }^{* *}$ denote significance at $5 \%$ and $10 \%$ level, respectively. 
Table 8. Statistics for the exchange rate, before and after 1997

\begin{tabular}{|c|c|c|c|c|c|c|c|c|}
\hline & \multicolumn{2}{|c|}{ Indonesia } & \multicolumn{2}{|c|}{ Japan } & \multicolumn{2}{|c|}{ Korea } & \multicolumn{2}{|c|}{ Malaysia } \\
\hline & Before & After & Before & After & Before & After & Before & After \\
\hline Sample size & 221 & 64 & 221 & 64 & 221 & 64 & 221 & 64 \\
\hline Mean & 0.259 & 0.803 & -0.055 & 0.385 & 0.048 & 0.406 & 0.150 & 0.637 \\
\hline SD & 2.802 & 12.718 & 3.176 & 3.263 & 1.495 & 6.478 & 1.254 & 3.814 \\
\hline Maximum & 30.590 & 61.263 & 11.348 & 6.253 & 16.175 & 34.978 & 5.145 & 14.890 \\
\hline Minimum & -6.068 & -26.369 & -10.207 & -14.124 & -4.092 & -16.268 & -4.289 & -15.417 \\
\hline \multirow[t]{2}{*}{ Skewness } & $7.982 *$ & $1.629 *$ & $-0.378^{*}$ & $-1.501^{*}$ & $5.571^{*}$ & $2.332 *$ & 0.193 & -0.030 \\
\hline & $(0.165)$ & $(0.306)$ & $(0.165)$ & $(0.306)$ & $(0.165)$ & $(0.306)$ & $(0.165)$ & $(0.306)$ \\
\hline \multirow[t]{2}{*}{ Kurtosis } & $79.374 *$ & $10.215^{*}$ & $3.700 *$ & $7.723^{*}$ & $62.879 *$ & $15.348 *$ & $5.078^{*}$ & $10.778 *$ \\
\hline & $(0.330)$ & $(0.612)$ & $(0.330)$ & $(0.612)$ & $(0.330)$ & $(0.612)$ & $(0.330)$ & $(0.612)$ \\
\hline \multirow[t]{3}{*}{ J-B N } & $56059.030 *$ & $167.112 *$ & $9.782 *$ & $83.518^{*}$ & $34159.210^{*}$ & $464.596^{*}$ & $41.137 *$ & $158.826^{*}$ \\
\hline & \multicolumn{2}{|c|}{ Philippines } & \multicolumn{2}{|c|}{ Singapore } & \multicolumn{2}{|c|}{ Taiwan } & \multicolumn{2}{|c|}{ Thailand } \\
\hline & Before & After & Before & After & Before & After & Before & After \\
\hline Sample size & 221 & 64 & 221 & 64 & 221 & 64 & 221 & 64 \\
\hline Mean & 0.010 & 0.817 & -0.024 & 0.496 & -0.084 & 0.500 & 0.035 & 0.790 \\
\hline SD & 3.157 & 3.996 & 1.347 & 2.293 & 1.398 & 2.062 & 1.385 & 4.911 \\
\hline Maximum & 23.133 & 13.609 & 4.850 & 6.518 & 5.399 & 8.643 & 15.155 & 16.295 \\
\hline Minimum & -9.373 & -9.129 & -5.248 & -7.434 & -6.159 & -6.964 & -2.685 & -15.911 \\
\hline \multirow[t]{2}{*}{ Skewness } & $3.050 *$ & $0.610^{*}$ & -0.143 & $-0.417 * *$ & $-0.273 *$ & 0.172 & $6.369^{*}$ & $0.460 * *$ \\
\hline & $(0.165)$ & $(0.306)$ & $(0.165)$ & $(0.306)$ & $(0.165)$ & $(0.306)$ & $(0.165)$ & $(0.306)$ \\
\hline \multirow[t]{2}{*}{ Kurtosis } & $23.046^{*}$ & $4.675^{*}$ & $5.021 *$ & $4.844^{*}$ & $5.648^{*}$ & $7.751^{*}$ & $67.672 *$ & $7.195^{*}$ \\
\hline & $(0.330)$ & $(0.612)$ & $(0.330)$ & $(0.612)$ & $(0.330)$ & $(0.612)$ & $(0.330)$ & $(0.612)$ \\
\hline J-B N & $4042.906^{*}$ & $11.449 *$ & $38.349^{*}$ & $10.920 *$ & $67.306^{*}$ & $60.503^{*}$ & $40007.650 *$ & $49.182 *$ \\
\hline
\end{tabular}

Before and after represent 1979:2-1997:6 and 1997:7-2002:10, respectively. SD represents standard deviation; J-B N denotes Jarque-Bera normality test. $*$ and $* *$ denotes $5 \%$ and $10 \%$ level of significance. 

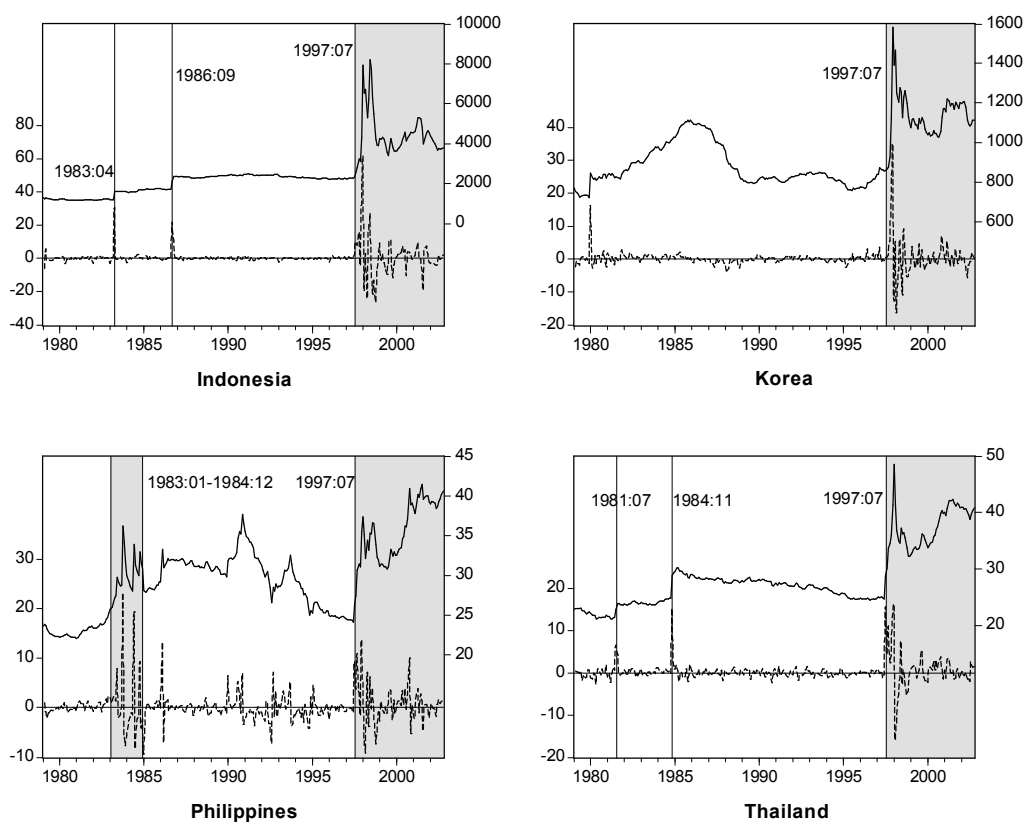

- Real Exchange Rate
---- Change of Real Exchange Rate(\%)

Figure 1. Structural changes for four exchange rates 

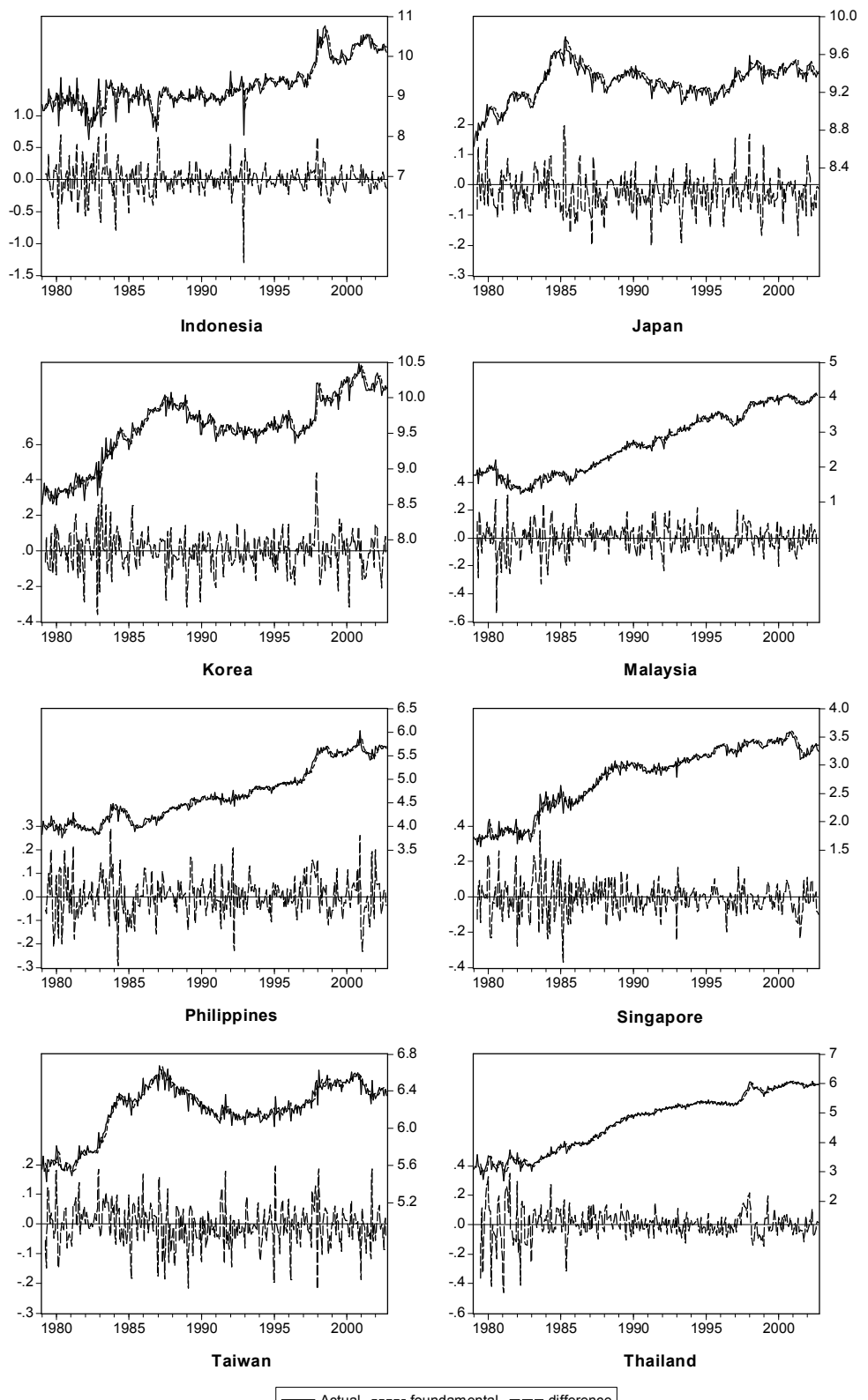

Figure 2. Difference between actual and fundamental exports 


\section{References}

Abeysinghe, T. and T.L. Yeok (1998) "Exchange Rate Appreciation and Export Competitiveness: The Case of Singapore," Applied Economics 30, 51-55.

Arize, A.C. (1995) "The Effects of Exchange-Rate Volatility on U.S. Exports: An Empirical Investigation," Southern Economic Journal 62, 34-43.

Arize, A.C. (1996) "Real Exchange-Rate Volatility and Trade Flows: The Experience of Eight European Economies," International Review of Economics and Finance 5, 187-205.

Arize, A.C. (1997) "Foreign Trade and Exchange-Rate Risk in the G-7 Countries: Cointegration and Error-Correction Models," Review of Financial Economics 6, 95-112.

Arize, A.C., T. Osang, and D.J. Slottje, (2000) "Exchange-Rate Volatility and Foreign Trade: Evidence From Thirteen LDC's," Journal of Business and Economic Statistics 18, 10-17.

Arize, A.C., J. Malindretos, and K.M. Kasibhatla (2003) "Does Exchange-Rate Volatility Depress Export Flows: The Case of LDCs," International Advances in Economics Research 9, 7-19.

Asseery, A. and D.A. Peel (1991) "The Effects of Exchange Rate Volatility on Exports: Some New Estimates,” Economics Letters 37, 173-177.

Athukorala, P. (1991) "Exchange Rate Pass-through: The Case of Korean Exports of Manufactures," Economic Letters 35, 79-84.

Athukorala, P. and J. Menon (1994) "Pricing to Market Behaviour and Exchange Rate Pass-though in Japanese Exports," The Economic Journal 104, 271-281.

Bahmani-Oskooee, M. and O. Kara. (2003) "Relative Responsiveness of Trade Flows to a Change in Prices and Exchange Rate," International Review of Applied Economics 17, 293-308.

Bollerslev, T. (1990) "Modeling the Coherence in Short-run Nominal Exchange Rates: A Multivariate Generalized ARCH Model," Review of Economics and Statistics 72, 
498-505.

Bollerslev, T., R.J. Chou, and K.F. Kroner (1992) “ARCH Modeling in Finance: A Review of the Theory and Empirical Evidence," Journal of Econometrics 52, 5-59.

Broll, U. and B. Eckwert (1999) "Exchange Rate Volatility and International Trade," Southern Economic Journal 66, 178-185.

Chowdhury, A. R. (1993) "Does Exchange Rate Volatility Depress Trade Flows? Evidence From Error-Correction Models," Review of Economics and Statistics 75, 700-706.

De Grauwe, P. (1988) "Exchange Rate Variability and The Slowdown in Growth of International Trade," IMF Staff Papers 35, 63-84.

Engle, R. F., D.M. Lilien, and R.P. Robins (1987) “Estimating Time-Varying Risk Premia in the Term Structure: The ARCH-M Model," Econometrica 55, 391-407.

Ethier, W. (1973) "International Trade and the Forward Exchange Market," American Economic Review 63, 494-503.

Fang, W. and H. Thompson (2004) "Exchange Rate Risk and Export Revenue in Taiwan," Pacific Economic Review 9, 117-129.

Frömmel, M. and L. Menkhoff (2001) "Risk Reduction in the EMS? Evidence from Trends in Exchange Rate Properties," Journal of Common Market Studies, 39, 285-306.

Hodrick, R.J. and S. Srivastava (1984) “An Investigation of Risk and Return in Forward Foreign Exchange," Journal of International Money and Finance 3, 5-29.

Hosking, J.R.M. (1980) “The Multivariate Portmanteau Statistic," Journal of the American Statistical Association, 75, 602-608.

Hughes, Hallett, A. and M. L. Anthony (1997) "Exchange Rate Behaviour under the EMS Regime: Was there any Systematic Change?” Journal of International Money and Finance, 16, 537-560. 
Junz, H. and R.R. Rhomberg (1973) "Price Competitiveness in Export Trade among Industrial Countries," American Economic Review, Papers and Proceedings 63, 412-418.

Klaassen, F. (2004) "Why is it so Difficult to Find an Effect of Exchange Rate Risk on Trade?” Journal of International Money and Finance, 23, 817-839.

Kroner, K.F. and W.D. Lastrapes (1993) "The Impact of Exchange Rate Volatility on International Trade: Reduced Form Estimates Using the GARCH in Mean Model," Journal of International Money and Finance 12, 298-318.

McKenzie, M.D. and R.D. Brooks (1997) "The Impact of Exchange Rate Volatility on German-U.S. Trade Flow," Journal of International Financial Markets, Institutions and Money 7, 73-87.

Perron, P. (1989) "The Great Crash, the Oil Price Shock and the Unit Root Hypothesis," Econometrica 57, 1361-1401.

Perron, P. (1997) "Further Evidence on Breaking Trend Functions in Macroeconomic Variables," Journal of Econometrics 80, 355-385.

Pozo, S. (1992) "Conditional Exchange-Rate Volatility and the Volume of International Trade: Evidence from the Early 1990s," Review of Economics and Statistics 74, 325-329.

Rose, A. (1990) "Exchange Rates and the Trade Balance: Some Evidence from Developing Countries," Economics Letters 34, 271-275.

Rose, A. and J. Yellon (1989) “Is There A J-curve?” Journal of Monetary Economics, 24, 53-68.

Tsay, R.S. (2002) Analysis of Financial Time Series, New York: John Wiley \& Sons.

Weliwita A., E.M. Ekanayake, and H. Tsujii (1999) "Real Exchange Rate Volatility and Sri Lanka's Exports to the Developed Countries, 1978-96," Journal of Economic Development 24, 147-165.

Wilson P. and K.C. Tat (2001) "Exchange rates and the trade balance: The case of Singapore 1970 to 1996," Journal of Asian Economics 12, 47-63. 
Wilson, J.F. and W.E. Takacs (1979) "Differential Responses to Price and Exchange Rate Influences in the Foreign Trade of Selected Industrial Countries," Review of Economics and Statistics 61, 267-279. 